\title{
CKDu: A Perfect Storm
}

When chronic kidney disease (CKD) rates began to climb in poor agricultural communities in Central America and elsewhere at least a decade ago, no one could have predicted the devastation wrought since then by what appears to be a new form of nephropathy. An epidemic that in a country such as El Salvador has catapulted end-stage renal disease to third place among causes of hospital deaths, first place among men.

Termed alternately CKD of nontraditional causes, CKD of unknown etiology, agricultural nephropathy, chronic agrochemical nephropathy, Mesoamerican epidemic nephropathy, and CKD of uncertain etiology-its effects are the same and its characterization similar in the countries where it has emerged. Most often described histopathologically as chronic tubulointerstitial nephritis, this CKD has thus far been studied in El Salvador, Nicaragua, Costa Rica, Mexico, Sri Lanka, Egypt and India. We prefer CKD of uncertain etiology (CKDu), since initial research findings point to multifactorial causation in nearly all cases.

And it is the multifactorial mystery that has generated a perfect storm, in which social determinants such as deep-rooted poverty appear to combine synergistically with harsh, sometimes inhuman, working conditions and exposure to environmental toxins to produce a silent killer that is most often diagnosed when kidney damage already requires renal replacement therapy. This is too late for most of these subsistence farmers and agricultural laborers, since the cost of such treatment is simply out of reach, and they often have little access to the range of specialties required to manage their disease.

The brewing storm is complicated by the fact that the people and communities affected are in developing countries, the least able to provide the infrastructure or financial resources for urgently needed health services such as dialysis and transplantation. In the best of cases, governments and health ministries have sounded the alarm and taken action within their means; in the worst of cases, people who suffer are not only threatened by illness, but their protests are also repressed by misguided government authorities.

Researchers have yet to agree on the trigger for CKDu or the exact configuration of its risk factors. The debates are heated and many vested interests surely will be touched upon as they proceed, making full disclosure by researchers more ethically essential than ever. Critically important to move forward are coordinated research agendas that respect differing results and eschew professional rivalries. The race is not to be first or to be right, after all, but to halt the loss of lives. In this context, public health actions are required to intercede to protect lives, even before the final results are in on CKDu causal relationships... if they ever are. This means exercising the precautionary principle when necessary, and clearly implies the need for greater attention and cooperation from international agencies such as PAHO and $\mathrm{WHO}$, as well as health ministries, research centers, NGOs, labor, industry and foundations.

We hope this issue of MEDICC Review contributes to advancing collaboration to stem this alarming epidemic, by publishing the latest findings on CKDu and its global impact. In addition to Original Research and Perspectives by authors in five countries, we are grateful to the major figures in public health and nephrology who found the time to express their superb Viewpoints in the pages that follow. We call your attention to the sections available online only: in particular the Special Abstracts Section on CKDu, intended as a repository for articles related to the disease published in peer-reviewed journals, and for which we invite additions to update readers (see www.medicc.org/mediccreview). Also noteworthy are online reprints of several important documents stemming from regional meetings, as well as the Concept Paper and Resolution approved by PAHO's Executive Committee, providing a framework to address the epidemic.

"Dr Miguel Márquez, one of this hemisphere's public health luminaries and a member of MEDICC Review's Editorial Board, passed away on February 3. Born in Ecuador in 1934, he studied medicine at the University of Cuenca, went on to earn a master's degree at the University del Valle in Colombia, and to work for many years in the Pan American Health Organization (PAHO) in human resources for health and other key fields. He served as $\mathrm{PAHO} / \mathrm{WHO}$ country representative in both Nicaragua and Cuba, the latter through $1996 .$.

"He was a founding member of [the journal's] Editorial Board... generously contributing his extensive and profound experience. He authored or co-authored over 80 major publications, including the UNDP's Human Development in Cuba (Spanish, three editions); [and] a book on the Cuban health system (Salud para todos, sí es posible).

"The hemisphere has lost a great man, a defender of vulnerable populations and the importance of strengthening health systems to serve them."

For the full note from our publisher on Dr Márquez's life, see http://medicc.org/ns/?p=1015

We congratulate two of our Editorial Board members for recent achievements: Dr Francisco Rojas Ochoa, recognized by the Cuban medical sciences publishing community for his decades of dedication to medical and public health research and debate, most recently as editor of the Revista Cubana de Salud Pública, a post from which he is now retiring. And accolades go to Dr Raúl Herrera, recently awarded the Carlos J. Finlay Medal, the highest honor in Cuban public health.

Our thanks to The Ford Foundation and The Atlantic Philanthropies, a limited life foundation, for supporting this special issue.

The entire MEDICC Review team is grateful for the wise counsel and exceptional editorial contribution to this issue provided by Guest Editor Dr Wendy Hoy, whose life's work offers an example of scientific rigor at the service of disadvantaged people. -1 -

\section{The Editors}

